Article

\title{
Tetraphenylpyrimidine-Based AIEgens: Facile Preparation, Theoretical Investigation and Practical Application
}

\author{
Junkai Liu ${ }^{1,2}$, Lingxiang Pan ${ }^{1}$, Qian Peng ${ }^{2, *}$ and Anjun Qin ${ }^{1, *}$ \\ 1 State Key Laboratory of Luminescent Materials and Devices, South China University of Technology, \\ Guangzhou 510640, China; ipowerjkl@outlook.com (J.L.); panlx2014@hotmail.com (L.P.) \\ 2 Key Laboratory of Organic Solids, Beijing National Laboratory for Molecular Sciences, \\ Institute of Chemistry, Chinese Academy of Sciences, Beijing 100190, China \\ * Correspondence: qpeng@iccas.ac.cn (Q.P.); msqinaj@scut.edu.cn (A.Q.); \\ Tel.: +86-10-8261-6830 (Q.P.); +86-20-2223-7065 (A.Q.)
}

Received: 20 August 2017; Accepted: 3 October 2017; Published: 10 October 2017

\begin{abstract}
Aggregation-induced emission (AIE) has become a hot research area and tremendous amounts of AIE-active luminogens (AIEgens) have been generated. To further promote the development of AIE, new AIEgens are highly desirable. Herein, new AIEgens based on tetraphenylpyrimidine (TPPM) are rationally designed according to the AIE mechanism of restriction of intramolecular motion, and facilely prepared under mild reaction conditions. The photophysical property of the generated TPPM, TPPM-4M and TPPM-4P are systematically investigated and the results show that they feature the aggregation-enhanced emission (AEE) characteristics. Theoretical study shows the high-frequency bending vibrations in the central pyrimidine ring of TPPM derivatives dominate the nonradiative decay channels. Thanks to the AEE feature, their aggregates can be used to detect explosives with super-amplification quenching effects, and the sensing ability is higher than typical AIE-active tetraphenylethene. It is anticipated that TPPM derivatives could serve as a new type of widely used AIEgen based on their facile preparation and good thermo-, photo- and chemostabilities.
\end{abstract}

Keywords: tetraphenylpyrimidine; aggregation-enhanced emission; restriction of intramolecular motion; structure-property relationship; explosive detection

\section{Introduction}

The research on aggregation-induced emission (AIE) is drawing increasing interest since it can solve the aggregation-caused quenching (ACQ) problem encountered by traditional organic luminophores. AIE-active luminogens (AIEgens) possess relatively high emission efficiency in the aggregate or solid states, which meets the requirements for practical applications in organic light-emitting diodes, optical waveguides, biosensors and bioimaging, etc. [1-8].

AIEgens exhibit remarkable advantages over traditional ACQ luminophores in aggregate and solid states, so constructing new AIEgens is of great importance for promoting the development of AIE research. Although enthusiastic efforts made by researchers have generated hundreds of AIEgens, many AIE cores contain cyclic or linear multiple vinyl groups in their structures. Ethylene derivatives may potentially encounter photo-oxidation and photobleaching problems. One effective strategy to improve stability is to construct AIEgens with sole aryl moieties. Meanwhile, the introduction of aromatic nitrogen heterocycles could help produce electron donor-acceptor structures to fine-tune the light emission in a wide range. Along these lines, tetraphenylpyrazine (TPP)-based AIEgens were designed based on the restriction of the intramolecular rotation mechanism and facilely synthesized 
under mild reaction conditions [9]. The TPP-based AIEgens exhibit remarkable advantages, such as facile preparation, efficient emission, good thermo-, photo- and chemostability $[10,11]$.

Inspired by the excellent performance of TPP derivatives, we designed and synthesized a new type of AIEgen based on the rarely explored tetraphenylpyrimidine (TPPM) (Chart 1). The central pyrimidine is anticipated to possess versatile functions such as protonation, hydrogen bond formation and chelation of the nitrogen atoms, which make the generated AIEgens applicable in developing advanced supramolecular assemblies and chemosensors [12]. Besides following the working mechanism of typical AIEgens, the TPPM undergoes intense high-frequency intramolecular bending motion in the pyrimidine ring, which contributes largely to the nonradiative decay channels. Accordingly, attaching electron-donating groups to the electron-withdrawing pyrimidine rings could extend the conjugation and rigidify the skeleton of the molecule, and suppress the high-frequency bending vibrations. As expected, the generated TPPM-4M and TPPM-4P attain higher luminescent efficiency in both solution and solid states than that of TPPM. Nanoaggregates based on TPPM derivatives show higher performance for detecting the picric acid with larger quenching constants than the typical AIEgen of tetraphenylethene (TPE). This is attributed to more efficient electron transfer processes originating from the formation of hydrogen bonds between pyrimidine rings of TPPM derivatives and the explosive molecules [13].

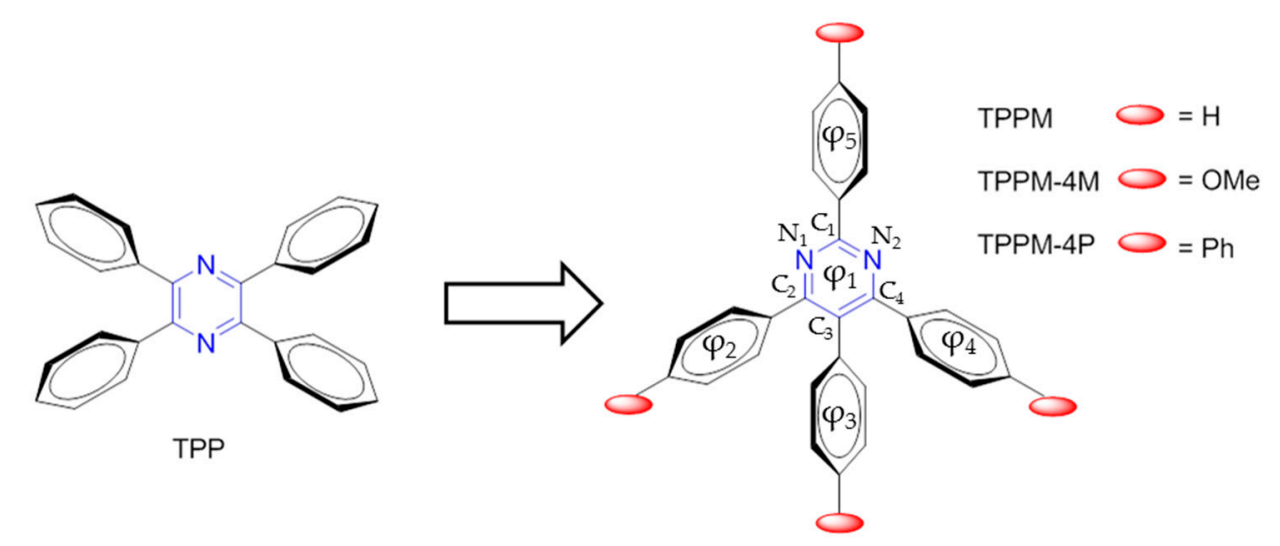

Chart 1. Molecular structures of AIEgens of tetraphenylpyrazine (TPP) and tetraphenylpyrimidine (TPPM) derivatives.

\section{Results and Discussion}

\subsection{General Routes for Synthesis of TPPM Derivatives}

The general routes to synthesize TPPM and its derivatives are shown in Scheme 1. Commercially available starting materials of tetrachloropyrimidine (1) and aromatic boronic acids (2-4) could be readily converted to TPPM or its derivatives of TPPM-4M and TPPM-4P in satisfactory yields through Suzuki coupling [14]. Satisfactory data corresponding to the target TPPM derivatives were obtained from the ${ }^{1} \mathrm{H}$ - and ${ }^{13} \mathrm{C}-\mathrm{NMR}$, high-resolution mass measurements (Figures S1-S9). These compounds are constructed by aromatic moieties, which greatly enhance their thermal stability. The rapid drops on the thermal-gravity analysis (TGA) curves can be ascribed to the sublimation of samples (Figure S10). Therefore, we define the temperature of $5 \%$ loss of weight as $T_{s \mathrm{~m}}$, measured to be $258{ }^{\circ} \mathrm{C}, 345^{\circ} \mathrm{C}$, and $466^{\circ} \mathrm{C}$ for TPPM, TPPM-4M and TPPM- 4 P, respectively. 


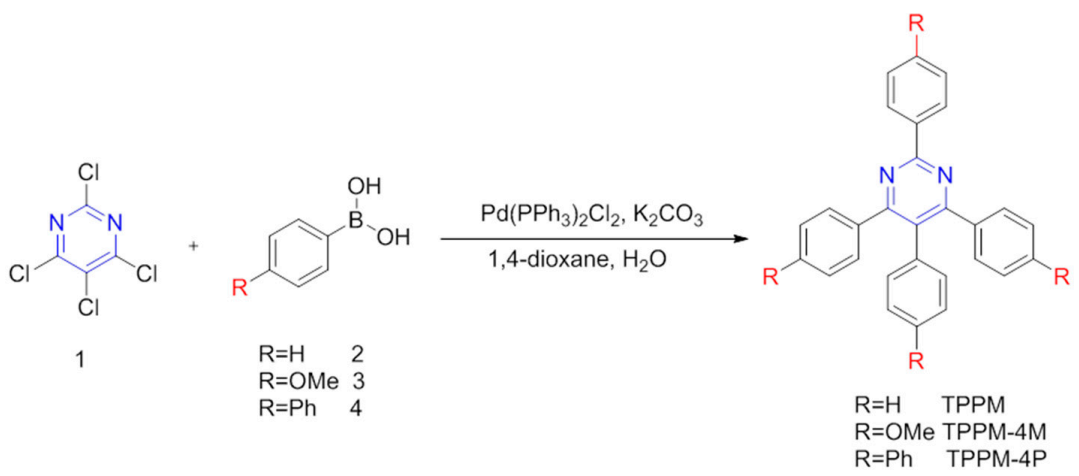

Scheme 1. Synthetic routes to tetraphenylpyrimidine (TPPM) and its derivatives.

\subsection{Photophysical Property of TPPM-Based AIEgens}

After confirming their structures, we investigated the photophysical properties of TPPM derivatives. We first measured their UV-vis absorption, shown in Figure 1. From TPPM to TPPM-4M and TPPM-4P, the maximum absorption peaks $\left(\lambda_{a b s}\right)$ red shift from 259 to $301 \mathrm{~nm}$ because decorating TPPM with electron-donating methoxyl groups or additional phenyl rings readily extends the conjugation and facilitates the charge transfer from methoxyl groups or phenyl rings to the central pyrimidine core upon excitation. Meanwhile, the maximum molar absorbance is also improved owing to the extension of conjugation in TPPM-4M and TPPM-4P. These conclusions are supported by the theoretical calculation shown in Tables S1-S3. Furthermore, we measured the absorbance spectra in different solvents. The results show that the $\lambda_{a b s}$ exhibit negligible shifts (Figures S11-S13).

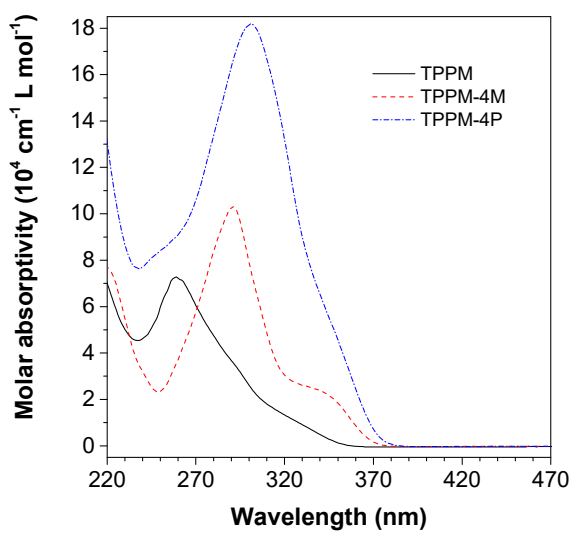

Figure 1. UV-vis absorption of TPPM and its derivatives in THF.

Next, we investigated the photoluminescence (PL) behaviors of TPPM and its derivatives in the THF/water mixture with different water fraction $\left(f_{w}\right)$. Taking TPPM as an example (Figure 2a), its emission intensity enhances gradually with increasing $f_{w}$ from 0 to $70 \%$. Afterwards, it rises markedly. The other derivatives show similar phenomena (Figures S14 and S15). These indicate that TPPM and its derivatives feature the unique aggregation-enhanced emission (AEE) characteristics. The fluorescence quantum yields $\left(\Phi_{\mathrm{F}}\right)$ measurement further confirmed their AEE feature. As shown in Figure $2 b$, the $\Phi_{\mathrm{F}}$ values of three compounds increase in the THF/ water mixtures with $f_{w}$ changing from 0 to $99 \%$, although negligible fluctuation appears in the curves. Furthermore, the $\Phi_{\mathrm{F}}$ values of TPPM, TPPM-4M and TPPM-4P powders are recorded to be $3.7 \%, 8.8 \%$ and $6.2 \%$, respectively (Table S4). Interestingly, although negligible shift was observed in the absorbance spectra, the maximum emission peaks $\left(\lambda_{e m}\right)$ of TPPM-4M and TPPM-4P exhibit an obvious bathochromic shift with an increase in the solvent polarity, while that of TPPM remains unchanged, which accounts for the enhanced charge transfer in TPPM derivatives by attaching the electron-donating groups. 


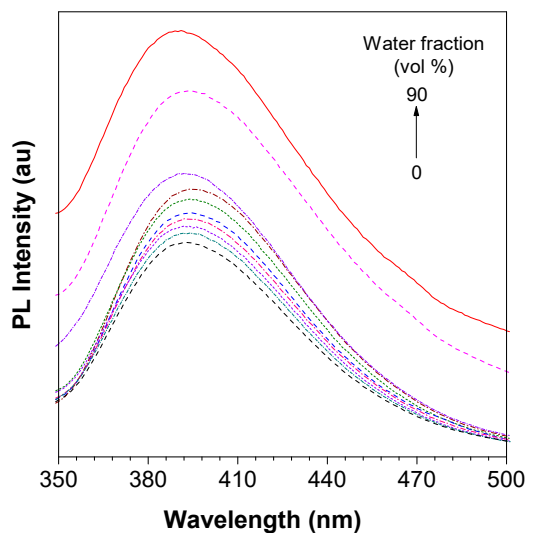

(a)

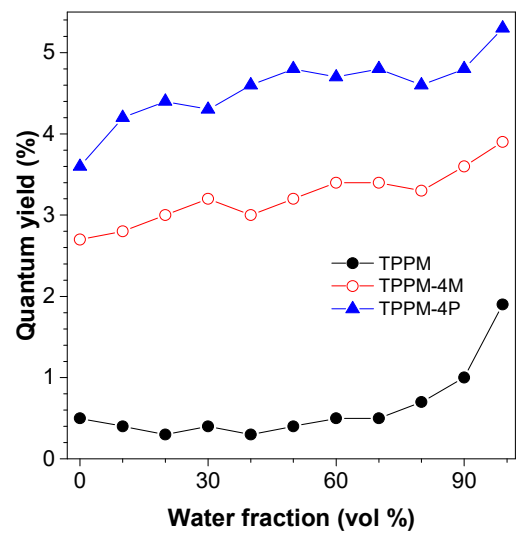

(b)

Figure 2. (a) PL spectra of TPPM in THF/water mixtures with different water fraction. Concentration: $10^{-5} \mathrm{M}, \lambda_{\text {ex }}=300 \mathrm{~nm}$; (b) Fluorescence quantum yields of TPPM and its derivatives vs. water fraction in $\mathrm{THF} /$ water mixtures.

\subsection{Working Mechanism}

We conducted a systematical theoretical investigation on the structure-property relationship of the TPPM derivatives aiming at illuminating the photo-physical mechanism. It is found that the HOMO of TPPM is mainly localized over the $\varphi_{2}, \varphi_{3}, \varphi_{4}$ and the pyrimidine ring (Chart 1 and Figure 3a). After decorating with electron-donating methoxyl and phenyl groups, the charge density in HOMO is extended over these substituents and the energy increases in the order of TPPM, TPPM-4M and TPPM-4P. However, LUMO is mainly distributed on the $\varphi_{3}, \varphi_{4}$ and the central rings in both methoxyl and phenyl counterparts. The delocalization of LUMO increases in the order of TPPM-4M, TPPM and TPPM-4P, resulting in the decrease of energy in the same order. Overall, the energy gaps between HOMOs and LUMOs decrease in the order of TPPM, TPPM-4M and TPPM-4P. As expected, the calculated electric transition dipole moments increase from TPPM (1.17 Debye) to TPPM-4M (3.63 Debye) to TPPM-4P (5.54 Debye). As a consequence, the radiative rate constants of the three compounds increase in the order of TPPM, TPPM-4M and TPPM-4P (Figure 3b), which would contribute largely to the enhancement of the $\Phi_{\mathrm{F}}$ of TPPM derivatives in solution after decorating with methoxyl and phenyl groups. These results are in good agreement with the measurement of $\Phi_{\mathrm{F}}$ shown in Figure $2 b$.

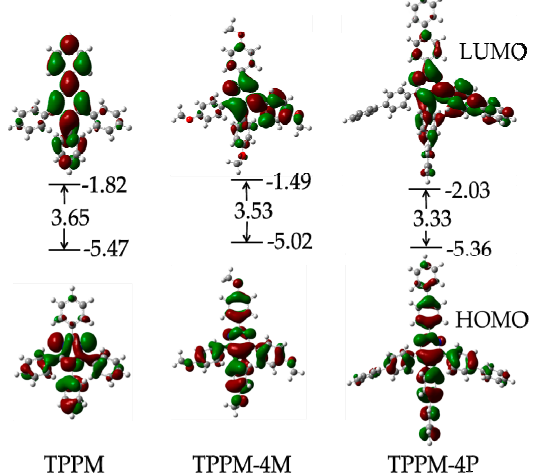

(a)

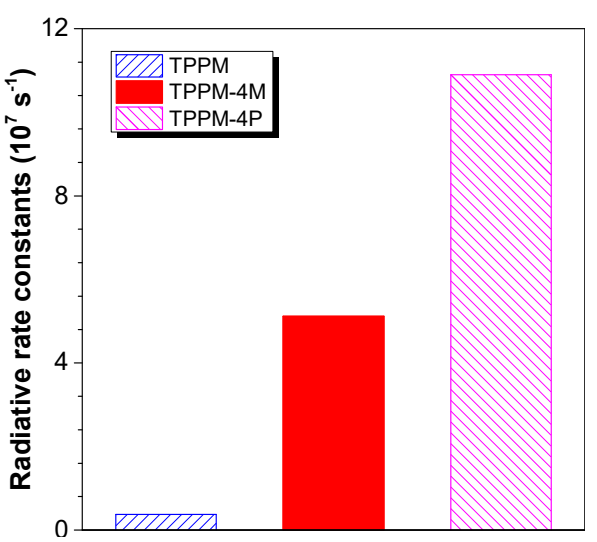

(b)

Figure 3. (a) Molecular orbital amplitude plots and energy levels of the HOMOs and the LUMOs of TPPM derivatives at the $\mathrm{S}_{1}$-geometry calculated at the B3LYP/6-31G $(\mathrm{d}, \mathrm{p})$ level; $(\mathbf{b})$ Comparison of radiative rate constants of TPPM, TPPM-4M and TPPM-4P calculated in the isolated state. 
The optimized molecular geometries of these three compounds are then examined and the data are listed in Table 1 and Table S5. It is obvious that the three compounds consist of a central stator and peripheral rotors, which are connected through single bonds. Relative to the central core, the peripheral phenyl rings $\varphi_{2}, \varphi_{3}$, and $\varphi_{4}$ are hugely twisted due to the high steric congestion while the $\varphi_{5}$ is almost planar without repulsion from adjacent groups at the $S_{0}$ state. The highly twisted conformation of the TPPM derivatives could prevent from close packing in the condensed phase and reduce the possibility of forming emission quenching species. Upon excitation, the largest modifications appear in dihedral angles between $\varphi_{2} / \varphi_{4}$ and $\varphi_{1}$ rings with the same decrease values of $13^{\circ}$ in TPPM, keeping the approximate C2 symmetry. While the dihedral angles between $\varphi_{3} / \varphi_{4}$ and $\varphi_{1}$ rings in the methoxyl and phenyl counterparts largely decrease with the values ranging from $11^{\circ}$ to $20^{\circ}$, thus breaking the molecular C2 symmetry. The $\varphi_{5}$ rings are still well conjugated with the central rings and the dihedral angles between $\varphi_{5}$ and $\varphi_{1}$ experience smallest variation upon excitation for all the three compounds. It is interesting that the bond angles in the pyrimidine ring experience intense modification upon excitation in TPPM, which has not been found in the reported AIEgens. The bond angles of central pyrimidine rings in three molecules are quite similar at $S_{0}$ states. Nevertheless, the bond angles $\mathrm{A}\left(\mathrm{C}_{1}-\mathrm{N}_{1}-\mathrm{C}_{2}\right), \mathrm{A}\left(\mathrm{C}_{1}-\mathrm{N}_{2}-\mathrm{C}_{4}\right)$, and $\mathrm{A}\left(\mathrm{N}_{1}-\mathrm{C}_{1}-\mathrm{N}_{2}\right)$ of TPPM change drastically with absolute values larger than $10^{\circ}$ from $S_{0}$ to $S_{1}$ states, which would activate some non-radiative decay channels. All bond angles of pyrimidine rings of TPPM-4M and TPPM-4P show slight variation.

Table 1. Selected dihedral angles and bond angles (in degree) for isolated TPPM, TPPM-4M, TPPM-4P molecules in the $S_{0}$ and the $S_{1}$ state.

\begin{tabular}{lccccccccc}
\hline & \multicolumn{3}{c}{ TPPM } & \multicolumn{3}{c}{ TPPM-4M } & \multicolumn{3}{c}{ TPPM-4P } \\
\cline { 2 - 11 } & $\mathbf{S}_{\mathbf{0}}$ & $\mathbf{S}_{\mathbf{1}}$ & $\boldsymbol{\Delta}\left(\mathbf{S}_{\mathbf{1}}-\mathbf{S}_{\mathbf{0}}\right)$ & $\mathbf{S}_{\mathbf{0}}$ & $\mathbf{S}_{\mathbf{1}}$ & $\boldsymbol{\Delta}\left(\mathbf{S}_{\mathbf{1}}-\mathbf{S}_{\mathbf{0}}\right)$ & $\mathbf{S}_{\mathbf{0}}$ & $\mathbf{S}_{\mathbf{1}}$ & $\boldsymbol{\Delta}\left(\mathbf{S}_{\mathbf{1}}-\mathbf{S}_{\mathbf{0}}\right)$ \\
\hline $\mathbf{D}\left(\boldsymbol{\varphi}_{\mathbf{1}}-\boldsymbol{\varphi}_{\mathbf{2}}\right)$ & 40 & 27 & -13 & 37 & 42 & 5 & 40 & 47 & 7 \\
$\mathbf{D}\left(\boldsymbol{\varphi}_{\mathbf{1}}-\boldsymbol{\varphi}_{\mathbf{3}}\right)$ & 63 & 65 & 2 & 62 & 49 & -13 & 62 & 42 & -20 \\
$\mathbf{D}\left(\boldsymbol{\varphi}_{\mathbf{1}}-\boldsymbol{\varphi}_{\mathbf{4}}\right)$ & 40 & 27 & -13 & 37 & 26 & -11 & 40 & 25 & -15 \\
$\mathbf{D}\left(\boldsymbol{\varphi}_{\mathbf{1}}-\boldsymbol{\varphi}_{\mathbf{5}}\right)$ & 4 & 7 & 3 & 5 & 7 & 2 & 4 & 7 & 3 \\
\hline $\mathbf{A}\left(\mathbf{C}_{\mathbf{1}}-\mathbf{N}_{\mathbf{1}}-\mathbf{C}_{\mathbf{2}}\right)$ & 118 & 128 & 10 & 118 & 117 & -1 & 118 & 117 & -1 \\
$\mathbf{A}\left(\mathbf{C}_{\mathbf{1}}-\mathbf{N}_{\mathbf{2}}-\mathbf{C}_{\mathbf{4}}\right)$ & 118 & 128 & 10 & 118 & 121 & 3 & 118 & 121 & 3 \\
$\mathbf{A}\left(\mathbf{N}_{\mathbf{1}}-\mathbf{C}_{\mathbf{2}}-\mathbf{C}_{\mathbf{3}}\right)$ & 122 & 121 & -1 & 122 & 123 & 1 & 122 & 123 & 1 \\
$\mathbf{A}\left(\mathbf{N}_{\mathbf{2}}-\mathbf{C}_{\mathbf{4}}-\mathbf{C}_{\mathbf{3}}\right)$ & 122 & 121 & -1 & 121 & 118 & -3 & 122 & 118 & -4 \\
$\mathbf{A}\left(\mathbf{N}_{\mathbf{1}}-\mathbf{C}_{\mathbf{1}}-\mathbf{N}_{\mathbf{2}}\right)$ & 125 & 111 & -14 & 125 & 125 & 0 & 125 & 125 & 0 \\
$\mathbf{A}\left(\mathbf{C}_{\mathbf{2}}-\mathbf{C}_{\mathbf{3}}-\mathbf{C}_{\mathbf{4}}\right)$ & 116 & 112 & -4 & 116 & 116 & 0 & 116 & 116 & 0 \\
\hline
\end{tabular}

The reorganization energy in the $S_{1} / S_{0}$ geometrical relaxations characterizes the ability to produce internal conversion and provides essential details of the contribution from multiple intramolecular motions to the excited-state deactivation. Figure 4 illustrates the calculated reorganization energy versus the corresponding normal modes. It can be seen in TPPM that the high frequency modes contribute significantly to the total reorganization energy, which are predominantly ascribed to the stretching vibrations of $\mathrm{C}=\mathrm{C}$ and $\mathrm{C}=\mathrm{N}$ and the bending vibrations of bond angles in pyrimidine ring (Figure S16). Relative to that in TPPM, the total reorganization energy is found to decrease significantly, by about half in TPPM-4M and TPPM-4P, which implies the non-radiative decay would become much slower. Moreover, the contribution of bending motions turns weak and that of the low-frequency normal modes become dominant in TPPM-4M and TPPM-4P. The low-frequency modes are assigned as the rotational motions of the periphery phenyl rings as illustrated in Figures S17 and S18.

Further casting the reorganization energy onto the internal coordination depicts a clear picture of the specific structure-property relationship. As shown in Figure 4d, the reorganization energy from bond angles takes the largest proportion at 78\% in TPPM, in which the bond angles in the pyrimidine core contributes as highly as $59 \%$ with the value of $3189 \mathrm{~cm}^{-1}$. This further confirms that the bending motions of the bond angles in the pyrimidine ring act as nonradiative decay channels and thus lead to low fluorescence quantum yields of TPPM in the dilute solution. Meanwhile, the contribution from 
bond angles to the reorganization energy are 12 and 9\%, in which those from pyrimidine rings are 5 and $4 \%$ with values of 145 and $108 \mathrm{~cm}^{-1}$, in TPPM-4M and TPPM-4P, respectively. This indicates that attaching the methoxyl and phenyl groups to TPPM mitigates the bending motions of the central core by extending the conjugation degree and rigidifying the conformation of the whole molecule, thus improving the emission efficiency in both solution and aggregates.

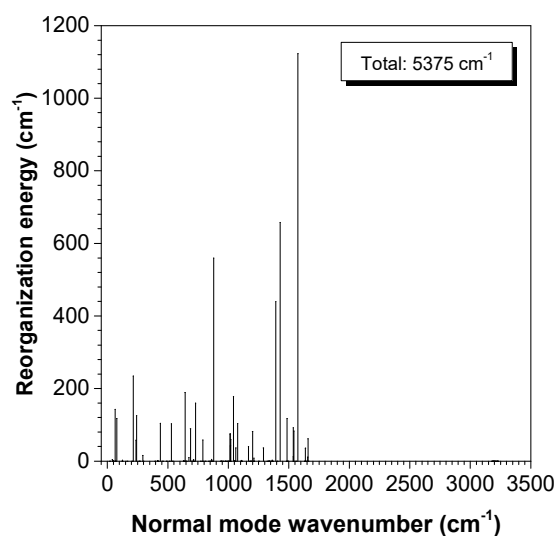

(a)

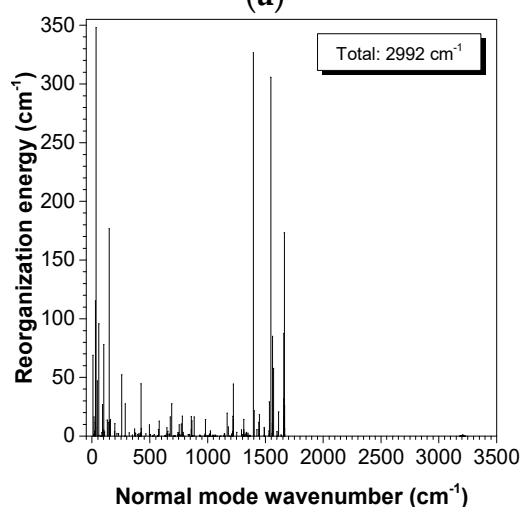

(c)

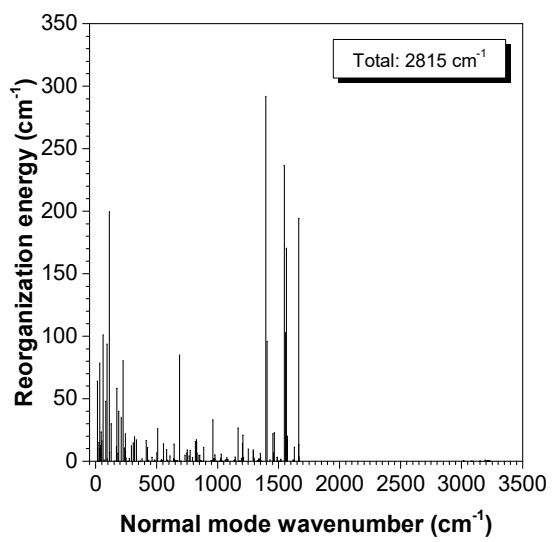

(b)

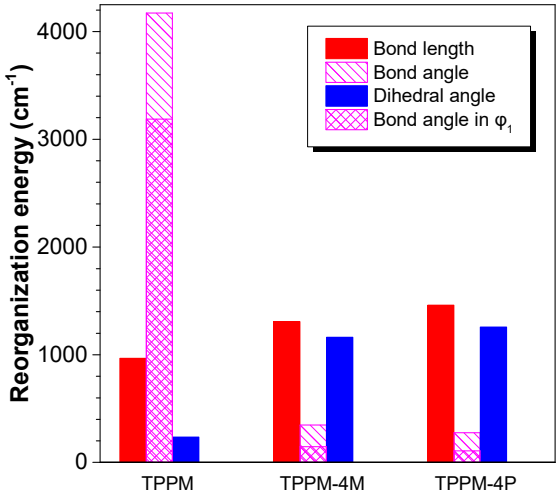

(d)

Figure 4. Presentation of the calculated reorganization energy versus the normal mode wavenumbers for (a) TPPM, (b) TPPM-4M, (c) TPPM-4P, and (d) contribution to the total reorganization energy from the bond length, the bond angle, the dihedral angle and the bond angle in the pyrimidine ring $\left(\varphi_{1}\right)$.

All three compounds present AEE phenomena as observed above. The light emission in the solid states of AIEgens is closely associated with the molecular packing modes [15-17]. We here take TPPM-4M as an example to figure out its mechanism and to establish the structure-property relationship. Figure 5 and Tables S6 and S7 provide the comparison of the molecular geometries at $S_{0}$ and $S_{1}$ states calculated in the gas and crystal phases, respectively. The calculated ground-state geometry in the solid phase is in good agreement with that in a single crystal, which indicates the rationality and reliability of the computational method adopted here. TPPM-4M adopts a twisted conformation with the dihedral angles between the peripheral phenyl rings and the central pyrimidine core ranging from 28 to $62^{\circ}$. Inspection of the single crystal packing manners shows that the highly twisted structure prevents molecules from close packing and multiple intermolecular $\mathrm{C}-\mathrm{H} \cdots \pi$ interactions exist among the molecules. The $\mathrm{C}-\mathrm{H} \cdots \pi$ interactions with the distances of $2.854 \AA$ between the $\varphi_{4}$ ring and the pyrimidine ring and of $3.029 \AA$ A between $\varphi_{3}$ and $\varphi_{4}$ generate effective constraint, and then the variation of dihedral angles of $\mathrm{D}\left(\varphi_{1}-\varphi_{2}\right), \mathrm{D}\left(\varphi_{1}-\varphi_{3}\right)$ and $\mathrm{D}\left(\varphi_{1}-\varphi_{4}\right)$ are as expected to be reduced to $0^{\circ}, 8^{\circ}$ and $4^{\circ}$, respectively (Figure $5 \mathrm{a}, \mathrm{b}$ ). Hence, TPPM- $4 \mathrm{M}$ in solid phase experiences less change compared with those in the gas phase, which would correspondingly cripple the non-radiative deactivation in the form of heat. 


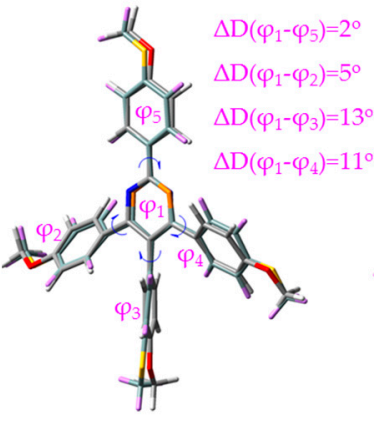

(a)

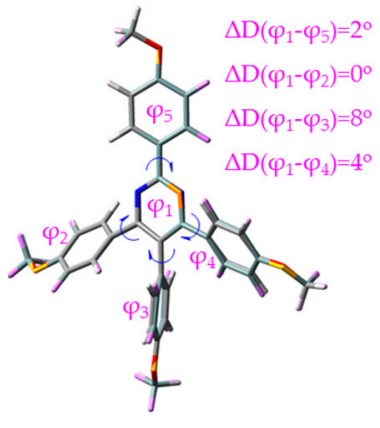

(b)

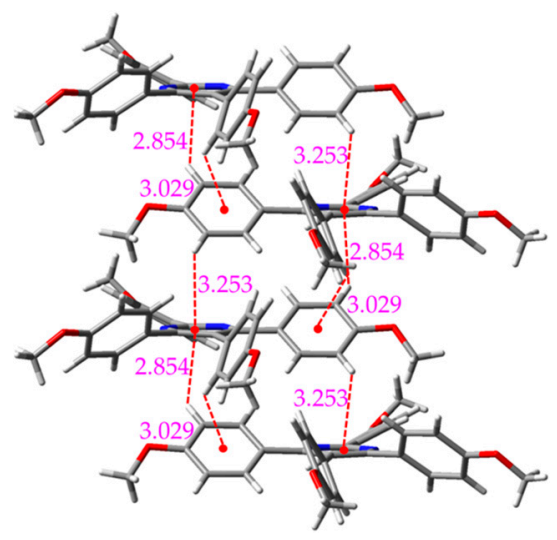

(c)

Figure 5. (a) Overlap diagram of optimized structures of $S_{0}$ and $S_{1}$ state of TPPM-4M in the gas phase and (b) in the crystal phase; (c) Single crystal packing diagram and intermolecular $\mathrm{C}-\mathrm{H} \cdots \pi$ interactions (in angstrom) of TPPM-4M.

The features of the geometrical modification are sure to produce different properties from the gas to the solid phase. It is most obvious that the total reorganization energy is reduced from 2815 in the gas phase to $2569 \mathrm{~cm}^{-1}$ in the crystal phase for TPPM-4M. The reorganization energy from bond lengths and bond angles in the gas phase almost equals to that in the crystal phase due to the similar variation pattern of these structural parameters. However, the reorganization energy from dihedral angles decreases from 1162 to $839 \mathrm{~cm}^{-1}$ (Figure 6), indicating the low-frequency rotational motion of peripheral phenyl groups is blocked. Hence, the calculated nonradiative decay rate constants decline sharply by five orders of magnitude in the condensed state, compared to the isolated state. The radiative rate constant of the condensed state is in the same magnitude as that of the isolated one because their electric transition dipole moments are close (Table 2). These evidently reveal the restriction of the non-radiative decay pathways and the enhancement of light emission in the aggregate state.

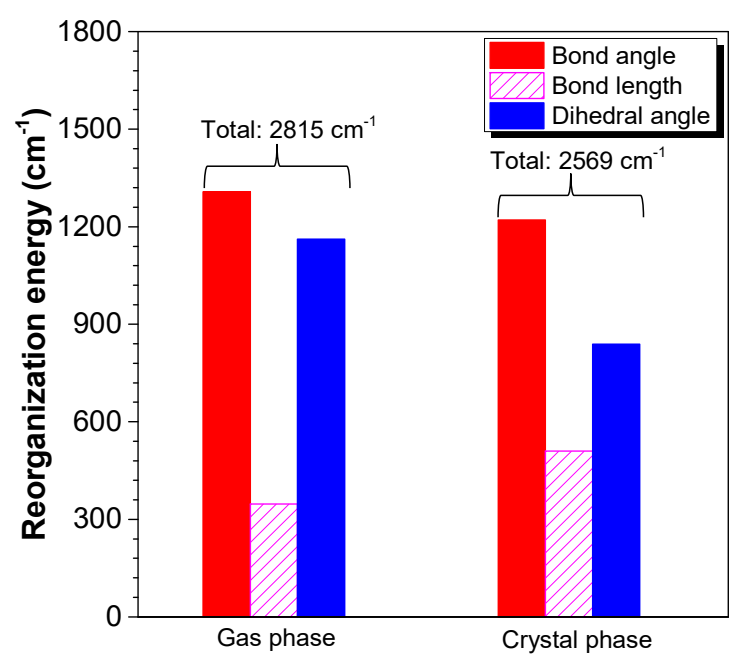

Figure 6. Contribution to the total reorganization energy in the gas and the crystal phase from the bond length, the bond angle, and the dihedral angle. 
Table 2. The calculated electric transition dipole moments $(\mu)$, radiative rate constants $\left(k_{r}\right)$ and nonradiative rate constants $\left(k_{i c}\right)$ of TPPM-4M in the gas phase and the crystal phase $(T=300 \mathrm{~K})$.

\begin{tabular}{cccc}
\hline $300 \mathrm{~K}$ & $\boldsymbol{\mu}$ (Debye) & $\boldsymbol{k}_{\boldsymbol{r}}\left(\mathrm{s}^{-\mathbf{1}}\right)$ & $\boldsymbol{k}_{\boldsymbol{i c}}\left(\mathrm{s}^{-\mathbf{1}}\right)$ \\
\hline Gas & 3.63 & $5.12 \times 10^{7}$ & $3.30 \times 10^{11}$ \\
Crystal & 3.21 & $3.54 \times 10^{7}$ & $2.34 \times 10^{6}$ \\
\hline
\end{tabular}

\subsection{Application in Explosive Detection}

Nanoaggregates of TPPM and its derivatives can serve as efficient fluorescent probes for explosive detection owning to their three-dimensional topological structures, which can generate numerous internal voids for interacting with analytes and migration pathways for excitons [18-20]. Herein, we chose the commercially available picric acid (PA) as a model explosive to monitor the variation of PL intensity of aggregates of TPPM derivatives in THF/water mixture $\left(f_{w}=99 \%\right)$. As shown in Figure 7a, the PL of TPPM-4M is progressively quenched with increasing PA concentration ([PA]). Obvious light annihilation was observed even at a [PA] as low as $0.5 \mathrm{ppm}$. At a [PA] of $0.39 \mathrm{mM}$, the emission is completely extinguished. The PL quenching spectra of the other two compounds are given in Figures S20-S22. Upward-bending variation curves were obtained in the Stern-Volmer plots of PL intensity ratio $\left(I_{0} / I\right)$ versus the PA concentration instead of straight lines. The quenching constants of 58,734, 41,703 and 32,269 $\mathrm{M}^{-1}$ of TPPM, TPPM-4M and TPPM-4P are deduced from the plots when PA concentration is below $0.1 \mathrm{mM}$, respectively, which are much higher than that of TPE of $9299 \mathrm{M}^{-1}$ (Inset in Figure $7 \mathrm{~b}$ ). The upward-bending curves in the Stern-Volmer plots after $0.1 \mathrm{mM}$ show the super-amplification quenching effect.

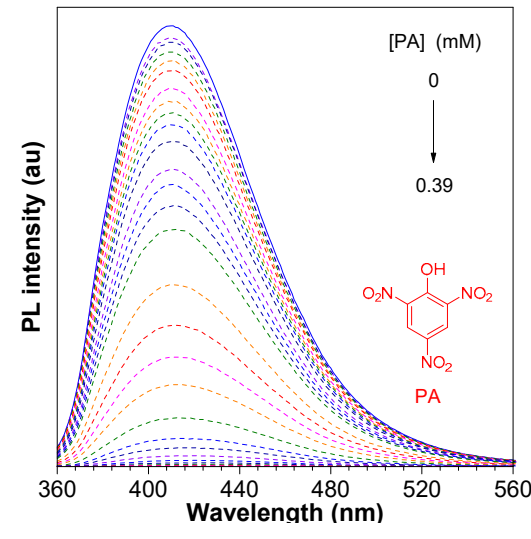

(a)

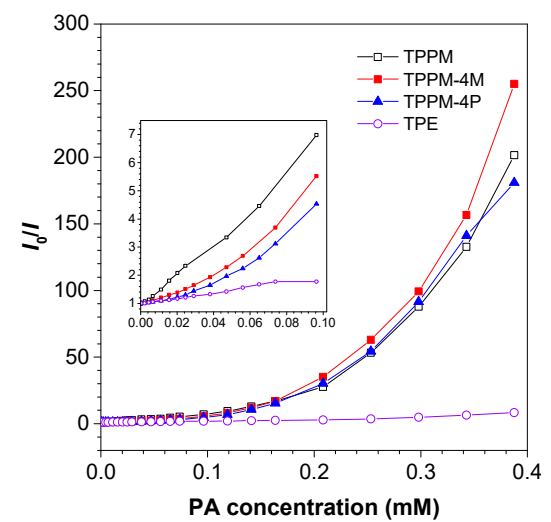

(b)

Figure 7. (a) PL spectra of TPPM-4M with addition of different amounts of PA in THF/water mixture $\left(f_{w}=99 \%\right)$. Concentration of TPPM-4M $=10^{-5} \mathrm{M}$. Excitation wavelength $=340 \mathrm{~nm}$. (b) Stern-Volmer plots of $I_{0} / I$ versus $[\mathrm{PA}]$ in THF/water mixture $\left(f_{w}=99 \%\right) . I=$ peak intensity. $I_{0}=$ peak intensity at $[\mathrm{PA}]=0 \mathrm{mM}$.

The fluorescence quenching could be generally ascribed to (i) the resonance energy transfer from the excited state of probe molecules to the ground state of analytes due to spectra overlap between emission bands of the former and absorption bands of the latter, and (ii) the photo-induced electron transfer (PET) from the probe to PA [21-24]. As can be seen in Figure 8a, all the emission bands of TPPM derivatives and TPE overlap with the absorption bands of PA, indicating that the resonance energy transfer could contribute largely to the PL quenching process. However, the more remarkable sensitivity of TPPM derivatives to PA, compared to TPE, is found to originate from the hydrogen-bond facilitated electron transfer process. The calculated relative positions between the probe and the PA are shown in Figure S23. The pyrimidine rings are able to form $\mathrm{N} \cdots$ H hydrogen 
bonds with PA molecules with distances ranging from 1.666 to 2.058 Á. The lower complexation energy between TPPM derivatives and the PA molecule than TPE reveals higher stability of such complexation patterns through hydrogen bonds between TPPM derivatives and the PA molecule (Table S8). The $\mathrm{N} \cdots \mathrm{H}$ hydrogen bonds can shorten the distance between fluorophores and PA molecules and facilitate electron transfer driven by the LUMO-LUMO offsets from probes to PA molecules (Figure 8b). Hence, TPPM derivatives attain larger quenching constants than TPE and show higher sensing performance for detecting explosives.

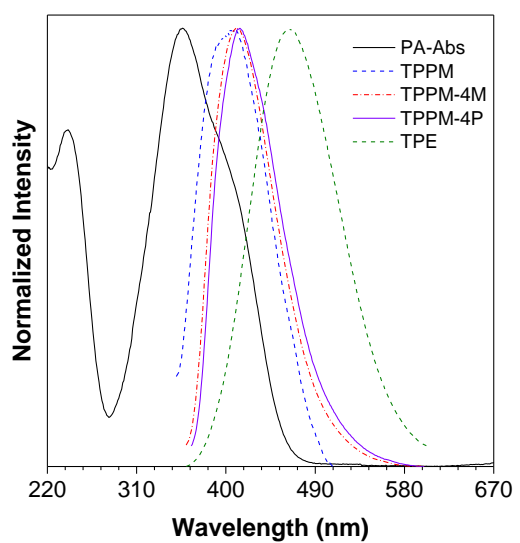

(a)

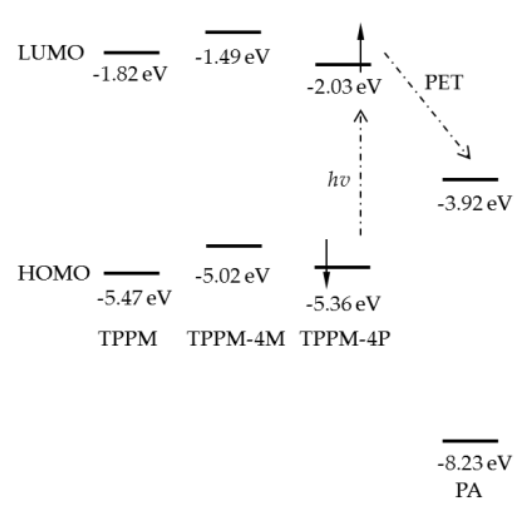

(b)

Figure 8. (a) Normalized UV-Vis absorption spectra of PA and PL spectra of TPPM, TPPM-4M, TPPM-4P and TPE in THF/water mixture $\left(f_{w}=99 \%\right)$; (b) Calculated energy level diagrams of TPPM derivatives and the PA.

\section{Materials and Methods}

\subsection{Synthesis of TPPM}

Tetrachloropyrimidine 1 ( $0.22 \mathrm{~g}, 1 \mathrm{mmol})$, phenylboronic acid 2 (0.54 g, $4.4 \mathrm{mmol}), \mathrm{Pd}\left(\mathrm{PPh}_{3}\right)_{2} \mathrm{Cl}_{2}$ $(0.035 \mathrm{~g}, 0.05 \mathrm{mmol})$, and $\mathrm{K}_{2} \mathrm{CO}_{3}(0.70 \mathrm{~g}, 5 \mathrm{mmol})$ were added to an oven-dried round bottom flask. The flask was filled with nitrogen. The 1,4-dioxane $(7.5 \mathrm{~mL})$ and distilled water $(2.5 \mathrm{~mL})$ were injected by syringe. The reaction mixture was stirred at $150{ }^{\circ} \mathrm{C}$ for $10 \mathrm{~h}$. After cooling to room temperature, the products were extracted with dichloromethane $(3 \times 25 \mathrm{~mL})$, and the organic layer was washed with water, dried over magnesium sulfate and filtration. Then the TPPM was isolated in a $81.6 \%$ yield $(0.31 \mathrm{~g})$ as a white solid through the silica-gel chromatographic column separation using a mixture of petroleum ether/dichloromethane as eluent and rotary evaporation under reduced pressure.

${ }^{1} \mathrm{H}-\mathrm{NMR}\left(500 \mathrm{MHz}, \mathrm{DMSO}-d_{6}\right): \delta$ (TMS, ppm) 8.57-8.47 (m, 2H), 7.64-7.51 (m, 3H), 7.42-7.16 (m, 13H), 7.12-7.04 (m, 2H). ${ }^{13} \mathrm{C}-\mathrm{NMR}\left(125 \mathrm{MHz}, \mathrm{DMSO}-d_{6}\right): \delta$ (TMS, ppm) 165.65, 162.15, 138.90, 137.55, 136.48, 131.38, 131.31, 129.97, 129.72, 129.20, 129.16, 128.62, 128.35, 128.21, 127.93. HRMS (MALDI-TOF): $m / z 385.1700\left([\mathrm{M}+\mathrm{H}]^{+}\right)$. Calcd for $\mathrm{C}_{28} \mathrm{H}_{21} \mathrm{~N}_{2} 385.1705$.

\subsection{Synthesis of TPPM- $4 M$}

Tetrachloropyrimidine 1 ( $0.22 \mathrm{~g}, 1 \mathrm{mmol})$, 4-methoxyl-phenylboronic acid 3 ( $0.67 \mathrm{~g}, 4.4 \mathrm{mmol})$, $\mathrm{Pd}\left(\mathrm{PPh}_{3}\right)_{2} \mathrm{Cl}_{2}(0.035 \mathrm{~g}, 0.05 \mathrm{mmol})$, and $\mathrm{K}_{2} \mathrm{CO}_{3}(0.70 \mathrm{~g}, 5 \mathrm{mmol})$ were added to an oven-dried round bottom flask. The flask was filled with nitrogen. The 1,4-dioxane $(7.5 \mathrm{~mL})$ and distilled water $(2.5 \mathrm{~mL})$ were injected by syringe. The reaction mixture was stirred at $150{ }^{\circ} \mathrm{C}$ for $10 \mathrm{~h}$. After cooling to room temperature, the products were extracted with dichloromethane $(3 \times 50 \mathrm{~mL})$, and the organic layer was washed with water, dried over magnesium sulfate and filtration. Then the TPPM-4M was isolated in a $78.0 \%$ yield $(0.39 \mathrm{~g})$ as a white solid through the silica-gel chromatographic column separation using dichloromethane as eluent and rotary evaporation under reduced pressure. 
${ }^{1} \mathrm{H}-\mathrm{NMR}\left(500 \mathrm{MHz}, \mathrm{DMSO}-d_{6}\right): \delta$ (TMS, ppm) 8.47-8.40 (m, 2H), 7.34-7.28 (m, 4H), 7.13-7.05 (m, 2H), 7.00-6.90 (m, 2H), 6.89-6.75 (m, 6H), $3.85(\mathrm{~s}, 3 \mathrm{H}), 3.75(\mathrm{~s}, 6 \mathrm{H}), 3.72(\mathrm{~s}, 3 \mathrm{H}) .{ }^{13} \mathrm{C}-\mathrm{NMR}(125 \mathrm{MHz}$, DMSO- $d_{6}$ ): $\delta$ (TMS, ppm) 164.89, 161.91, 161.58, 159.96, 158.77, 132.42, 131.56, 131.45, 130.34, 129.88, 127.71, 114.46, 114.39, 113.63, 55.78, 55.61, 55.45. HRMS (MALDI-TOF): $m / z 504.2036$ ([M] ${ }^{+}$). Calcd for $\mathrm{C}_{32} \mathrm{H}_{28} \mathrm{~N}_{2} \mathrm{O}_{4}$ 504.2049.

\subsection{Synthesis of TPPM-4P}

Tetrachloropyrimidine $\mathbf{1}(0.22 \mathrm{~g}, 1 \mathrm{mmol})$, biphenylboronic acid 4 ( $0.87 \mathrm{~g}, 4.4 \mathrm{mmol}), \mathrm{Pd}\left(\mathrm{PPh}_{3}\right)_{2} \mathrm{Cl}_{2}$ $(0.035 \mathrm{~g}, 0.05 \mathrm{mmol})$, and $\mathrm{K}_{2} \mathrm{CO}_{3}(0.70 \mathrm{~g}, 5 \mathrm{mmol})$ were added to an oven-dried round bottom flask. The flask was filled with nitrogen. The 1,4-dioxane $(7.5 \mathrm{~mL})$ and distilled water $(2.5 \mathrm{~mL})$ were injected by syringe. The reaction mixture was stirred at $150^{\circ} \mathrm{C}$ for $10 \mathrm{~h}$. After cooling to room temperature, the products were extracted with dichloromethane $(3 \times 25 \mathrm{~mL})$, and the organic layer was washed with water, dried over magnesium sulfate and filtration. Then the TPPM-4P was isolated in a $72.5 \%$ yield $(0.50 \mathrm{~g})$ as a white solid through the silica-gel chromatographic column separation using a mixture of petroleum ether/dichloromethane and rotary evaporation under reduced pressure.

${ }^{1} \mathrm{H}-\mathrm{NMR}\left(500 \mathrm{MHz}, \mathrm{CD}_{2} \mathrm{Cl}_{2}\right): \delta(\mathrm{TMS}, \mathrm{ppm}) 8.76(\mathrm{~d}, J=8.5 \mathrm{~Hz}, 2 \mathrm{H}), 7.80(\mathrm{~d}, J=8.5 \mathrm{~Hz}, 2 \mathrm{H})$, 7.76-7.71 (m, 2H), 7.65-7.29 (m, 28H), $7.21(\mathrm{~d}, J=8.3 \mathrm{~Hz}, 2 \mathrm{H}) .{ }^{13} \mathrm{C}-\mathrm{NMR}\left(125 \mathrm{MHz}, \mathrm{CD}_{2} \mathrm{Cl}_{2}\right)$ : $\delta$ (TMS, ppm) 166.42, 163.68, 144.58, 142.65, 141.79, 141.51, 141.39, 141.26, 139.08, 137.97, 137.00, 132.89, 131.82, 130.16, 130.15, 130.11, 130.08, 130.06, 129.03, 128.94, 128.82, 128.45, 128.40, 128.30, 128.21, 128.11, 127.67. HRMS (MALDI-TOF): $m / z$ 689.2876 ([M] $]^{+}$). Calcd for $\mathrm{C}_{52} \mathrm{H}_{36} \mathrm{~N}_{2} 689.2957$.

\subsection{Methods for Theoretical Calculation}

All the geometrical optimizations and frequency calculations were carried out using the (TD)B3LYP/6-31G $(\mathrm{d}, \mathrm{p})$ at the $\mathrm{S}_{0}\left(\mathrm{~S}_{1}\right)$ for the studied compounds in the gas phase in the Gaussian 09 package [25]. The corresponding calculations for them in the solid phase were performed using the combined quantum chemistry and molecular chemistry $(\mathrm{QM} / \mathrm{MM})$ approach. The $\mathrm{QM} / \mathrm{MM}$ model was set up by cutting a cluster containing 64 TPPM-4M molecules from the single crystal structure, the central molecule was treated as the QM part and the surrounding ones acted as the MM part. (Figure S19). The QM/MM calculation was performed by using the Chemshell 3.5 package [26], interfacing the Turbomole 6.5 [27] for QM at the B3LYP/6-31G(d) level and the DL_POLY [28] for MM with the general Amber force field (GAFF) [29]. The analytical frequencies for the $\mathrm{S}_{0}$ state at the DFT level and numerical frequencies for the $\mathrm{S}_{1}$ state at the TD-DFT level. The calculation of reorganization energy, radiative and nonradiative rate constants were carried out in the MOMAP package developed by Shuai group [30-35]. The formation of hydrogen bonds was evaluated by optimizing the relative position between the sensor molecule and the PA molecule at the $\omega \mathrm{B} 97 \mathrm{XD} / 6-31 \mathrm{G}(\mathrm{d}, \mathrm{p})$ level in the Gaussian 09 package.

\section{Conclusions}

A new type of AIEgen based on tetraphenylpyrimidine (TPPM) was rationally designed and facilely prepared. Theoretical investigation indicates that high-frequency bending motions of bond angles in the pyrimidine ring dominate the nonradiative decay process in TPPM. Attaching electron-donating methoxyl and phenyl groups to TPPM extends the conjugation and rigidifies the molecule skeleton and thus mitigates bending motion of the central core. As a result, relative to the TPPM, the reorganization energies of TPPM-4M and TPPM-4P are decreased sharply by more than half, greatly constraining the nonradiative decay. Meanwhile, the electric transition dipole moments of TPPM-4M and TPPM-4P are greatly enhanced, inducing faster radiative decay. Thus, the emission efficiency is promoted in both the solution and the solid state. Furthermore, multiple intermolecular interaction and steric hindrance existing in the aggregates block the low-frequency rotational motions of peripheral rotors and thus intensify the solid-state emission of TPPM derivatives. 
TPPM derivatives attain higher performance in sensing PA than the typical TPE, which is ascribed to the electron transfer process facilitated by the formation of hydrogen bonds between the pyrimidine and PA. Hence, nanoaggregates based on TPPM derivatives are fairly applicable in practical detection of explosive dissolved in water. Thus, these TPPM derivatives not only enrich the family of AIEgens but could also potentially be applied in optoelectronic and biological areas.

Supplementary Materials: The supplementary materials are available online.

Acknowledgments: This work was financially supported by the key project of the Ministry of Science and Technology of China (No. 2013CB834702), the National Natural Science Foundation of China (No. 21525417 and No. 21490571), the Natural Science Foundation of Guangdong Province (No. 2016A030312002), the National Program for Support of Top-Notch Young Professionals, the Fundamental Research Funds for the Central Universities (No. 2015ZY013). A.J.Q. and B.Z.T. thank the support from the Guangdong Innovative Research Team Program (No. 201101C0105067115).

Author Contributions: J.L. conducted the experiments and calculation; L.P. analyzed the data and discussed the findings; Q.P. guided the theoretical calculation and analyzed the data. A.Q. designed and guided the research work. All the authors wrote and revised the manuscript.

Conflicts of Interest: The authors declare no conflict of interest.

\section{References}

1. Mei, J.; Leung, N.L.C.; Kwok, R.T.K.; Lam, J.W.Y.; Tang, B.Z. Aggregation-Induced Emission: Together We Shine, United We Soar! Chem. Rev. 2015, 115, 11718-11940. [CrossRef] [PubMed]

2. Hu, F.; Zhang, G.X.; Zhan, C.; Zhang, W.; Yan, Y.L.; Zhao, Y.S.; Fu, H.B.; Zhang, D.Q. Highly Solid-State Emissive Pyridinium-Substituted Tetraphenylethylene Salts: Emission Color-Tuning with Counter Anions and Application for Optical Waveguides. Small 2015, 11, 1335-1344. [CrossRef] [PubMed]

3. Zhao, Q.L.; Li, K.; Chen, S.J.; Qin, A.J.; Ding, D.; Zhang, S.; Liu, Y.; Liu, B.; Sun, J.Z.; Tang, B. Aggregation-induced red-NIR emission organic nanoparticles as effective and photostable fluorescent probes for bioimaging. J. Mater. Chem. 2012, 22, 15128-15135. [CrossRef]

4. Dong, Y.Q.; Lam, J.W.Y.; Qin, A.J.; Liu, J.Z.; Li, Z.; Tang, B.Z. Aggregation-induced emissions of tetraphenylethene derivatives and their utilities as chemical vapor sensors and in organic light-emitting diodes. Appl. Phys. Lett. 2007, 91, 3. [CrossRef]

5. Li, Z. Fabrication of high-performance non-doped OLEDs by combining aggregation-induced emission and thermally activated delayed fluorescence. Sci. China Chem. 2017, 60, 1107-1108. [CrossRef]

6. Gao, Y.T.; Feng, G.X.; Jiang, T.; Goh, C.C.; Ng, L.G.; Liu, B.; Li, B.; Yang, L.; Hua, J.L.; Tian, H. Biocompatible Nanoparticles Based on Diketo-Pyrrolo-Pyrrole (DPP) with Aggregation-Induced Red/NIR Emission for In Vivo Two-Photon Fluorescence Imaging. Adv. Funct. Mater. 2015, 25, 2857-2866. [CrossRef]

7. Shi, X.Y.; Wang, H.; Han, T.Y.; Feng, X.; Tong, B.; Shi, J.B.; Zhi, J.G.; Dong, Y.P. A highly sensitive, single selective, real-time and "turn-on" fluorescent sensor for $\mathrm{Al}^{3+}$ detection in aqueous media. J. Mater. Chem. 2012, 22, 19296-19302. [CrossRef]

8. Liu, Z.T.; Xue, W.X.; Cai, Z.X.; Zhang, G.X.; Zhang, D.Q. A facile and convenient fluorescence detection of gamma-ray radiation based on the aggregation-induced emission. J. Mater. Chem. 2011, 21, 14487-14491. [CrossRef]

9. Mei, J.; Hong, Y.; Lam, J.W.Y.; Qin, A.; Tang, Y.; Tang, B.Z. Aggregation-Induced Emission: The Whole Is More Brilliant than the Parts. Adv. Mater. 2014, 26, 5429-5479. [CrossRef] [PubMed]

10. Chen, M.; Li, L.Z.; Nie, H.; Tong, J.Q.; Yan, L.L.; Xu, B.; Sun, J.Z.; Tian, W.J.; Zhao, Z.J.; Qin, A.J.; et al. Tetraphenylpyrazine-based AIEgens: Facile preparation and tunable light emission. Chem. Sci. 2015, 6, 1932-1937. [CrossRef] [PubMed]

11. Pan, L.X.; Luo, W.W.; Chen, M.; Liu, J.K.; Xu, L.; Hu, R.R.; Zhao, Z.J.; Qin, A.J.; Tang, B.Z. Tetraphenylpyrazine-Based Luminogens with Aggregation-Enhanced Emission Characteristics: Preparation and Property. Chin. J. Org. Chem. 2016, 36, 1316-1324. [CrossRef]

12. Achelle, S.; Plé, N. Pyrimidine Ring as Building Block for the Synthesis of Functionalized $\pi$-Conjugated Materials. Curr. Org. Synth. 2012, 9, 163-187. [CrossRef]

13. Li, D.D.; Yu, X. Mesoporous aluminium organophosphonates: A reusable chemsensor for the detection of explosives. J. Solid State Chem. 2016, 239, 17-22. [CrossRef] 
14. Hussain, M.; Hung, N.T.; Khera, R.A.; Malik, I.; Zinad, D.S.; Langer, P. Synthesis of Aryl-Substituted Pyrimidines by Site-Selective Suzuki-Miyura Cross-Coupling Reactions of 2,4,5,6-Tetrachloropyrimidine. Adv. Synth. Catal. 2010, 352, 1429-1433. [CrossRef]

15. Wang, C.; Li, Z. Molecular conformation and packing: Their critical roles in the emission performance of mechanochromic fluorescence materials. Mater. Chem. Front. 2017. [CrossRef]

16. Wang, C.; Xu, B.J.; Li, M.S.; Chi, Z.G.; Xie, Y.J.; Li, Q.Q.; Li, Z. A stable tetraphenylethene derivative: Aggregation-induced emission, different crystalline polymorphs, and totally different mechanoluminescence properties. Mater. Horizons 2016, 3, 220-225. [CrossRef]

17. Li, H.Y.; Chi, Z.G.; Xu, B.J.; Zhang, X.Q.; Li, X.F.; Liu, S.W.; Zhang, Y.; Xu, J.R. Aggregation-induced emission enhancement compounds containing triphenylamine-anthrylenevinylene and tetraphenylethene moieties. J. Mater. Chem. 2011, 21, 3760-3767. [CrossRef]

18. Wu, Y.; Qin, A.; Tang, B.Z. AIE-active polymers for explosive detection. Chin. J. Polym. Sci. 2016, 35, 141-154. [CrossRef]

19. Meher, N.; Iyer, P.K. Pendant chain engineering to fine-tune the nanomorphologies and solid state luminescence of naphthalimide AIEEgens: Application to phenolic nitro-explosive detection in water. Nanoscale 2017, 9, 7674-7685. [CrossRef] [PubMed]

20. Maity, S.; Shyamal, M.; Das, D.; Mazumdar, P.; Sahoo, G.P.; Misra, A. Aggregation induced emission enhancement from antipyrine-based schiff base and its selective sensing towards picric acid. Sens. Actuator B Chem. 2017, 248, 223-233. [CrossRef]

21. Dong, W.Y.; Pan, Y.Y.; Fritsch, M.; Scherf, U. High sensitivity sensing of nitroaromatic explosive vapors based on polytriphenylamines with AIE-active tetraphenylethylene side groups. J. Polym. Sci. Pol. Chem. 2015, 53, 1753-1761. [CrossRef]

22. Thomas, S.W.; Joly, G.D.; Swager, T.M. Chemical sensors based on amplifying fluorescent conjugated polymers. Chem. Rev. 2007, 107, 1339-1386. [CrossRef] [PubMed]

23. He, G.; Peng, H.N.; Liu, T.H.; Yang, M.N.; Zhang, Y.; Fang, Y. A novel picric acid film sensor via combination of the surface enrichment effect of chitosan films and the aggregation-induced emission effect of siloles. J. Mater. Chem. 2009, 19, 7347-7353. [CrossRef]

24. Feng, H.T.; Zheng, Y.S. Highly Sensitive and Selective Detection of Nitrophenolic Explosives by Using Nanospheres of a Tetraphenylethylene Macrocycle Displaying Aggregation-Induced Emission. Chem. Eur. J. 2014, 20, 195-201. [CrossRef] [PubMed]

25. Frisch, M.J.; Trucks, G.W.; Schlegel, H.B.; Scuseria, G.E.; Robb, M.A.; Cheeseman, J.R.; Scalmani, G.; Barone, V.; Mennucci, B.; Petersson, G.A.; et al. Gaussian09, Revision D.01; Gaussian Inc.: Wallingford, CT, USA, 2010.

26. Sherwood, P.; de Vries, A.H.; Guest, M.F.; Schreckenbach, G.; Catlow, R.C.A.; French, S.A.; Sokol, A.A.; Bromley, S.T.; Thiel, W.; Turner, A.J.; et al. QUASI: A General Purpose Implementation of the QM/MM Approach and Its Application to Problems in Catalysis. J. Mol. Struct. THEOCHEM 2003, 632, 1-28. [CrossRef]

27. Ahlrichs, R.; Bär, M.; Häser, M.; Horn, H.; Kölmel, C. Electronic Structure Calculations on Workstation Computers: The Program System Turbomole. Chem. Phys. Lett. 1989, 162, 165-169. [CrossRef]

28. Smith, W.; Forester, T.R. DL_POLY_2.0: A General-Purpose Parallel Molecular Dynamics Simulation Package. J. Mol. Graph. 1996, 14, 136-141. [CrossRef]

29. Wang, J.; Wolf, R.M.; Caldwell, J.W.; Kollman, P.A.; Case, D.A. Development and Testing of a General Amber Force Field. J. Comput. Chem. 2004, 25, 1157-1174. [CrossRef] [PubMed]

30. Shuai, Z.G.; Peng, Q.; Niu, Y.L.; Geng, H. MOMAP (Molecular Materials Property Prediction Package) is A Suite of Codes to Study the Spectroscopy; Revision 0.2.004; Shuai Group: Beijing, China, 2017; Available online: http:/ / www.momap.net.cn/ (accessed on 9 October 2017).

31. Shuai, Z.G.; Peng, Q. Excited states structure and processes: Understanding organic light-emitting diodes at the molecular level. Phys. Rep. Rev. Sec. Phys. Lett. 2014, 537, 123-156. [CrossRef]

32. Peng, Q.; Yi, Y.P.; Shuai, Z.G.; Shao, J.S. Toward quantitative prediction of molecular fluorescence quantum efficiency: Role of Duschinsky rotation. J. Am. Chem. Soc. 2007, 129, 9333-9339. [CrossRef] [PubMed]

33. Peng, Q.; Yi, Y.P.; Shuai, Z.G.; Shao, J.S. Excited state radiationless decay process with Duschinsky rotation effect: Formalism and implementation. J. Chem. Phys. 2007, 126, 114302. [CrossRef] [PubMed] 
34. Niu, Y.L.; Peng, Q.; Deng, C.M.; Gao, X.; Shuai, Z.G. Theory of Excited State Decays and Optical Spectra: Application to Polyatomic Molecules. J. Phys. Chem. A 2010, 114, 7817-7831. [CrossRef] [PubMed]

35. Niu, Y.; Peng, Q.; Shuai, Z. Promoting-mode free formalism for excited state radiationless decay process with Duschinsky rotation effect. Sci. China Ser. B Chem. 2008, 51, 1153-1158. [CrossRef]

Sample Availability: Samples of the compounds are not available from the authors.

(C) 2017 by the authors. Licensee MDPI, Basel, Switzerland. This article is an open access article distributed under the terms and conditions of the Creative Commons Attribution (CC BY) license (http://creativecommons.org/licenses/by/4.0/). 